\title{
Visions of the Possible: Reflections on the Faculty/Student Co- Inquirer Relationship
}

\author{
Mary Smyers \\ Illinois State University, mmsmyer@ilstu.edu \\ Jennifer Friberg \\ Illinois State University, jfribe@ilstu.edu \\ Lisa A. Vinney \\ Illinois State University, lavinne@ilstu.edu \\ DOI: doi.org/10.30707/TLCSD2.1Smyers
}

Follow this and additional works at: https://ir.library.illinoisstate.edu/tlcsd

Part of the Scholarship of Teaching and Learning Commons

\section{Recommended Citation}

Smyers, Mary; Friberg, Jennifer; and Vinney, Lisa A. (2018) "Visions of the Possible: Reflections on the Faculty/Student Co-Inquirer Relationship," Teaching and Learning in Communication Sciences \& Disorders: Vol. 2: Iss. 1, Article 3. DOI: doi.org/10.30707/TLCSD2.1Smyers

Available at: https://ir.library.illinoisstate.edu/tlcsd/vol2/iss1/3

This Student Voices is brought to you for free and open access by ISU ReD: Research and eData. It has been accepted for inclusion in Teaching and Learning in Communication Sciences \& Disorders by an authorized editor of ISU ReD: Research and eData. For more information, please contact ISUReD@ilstu.edu. 


\title{
Visions of the Possible: Reflections on the Faculty/Student Co-Inquirer Relationship
}

\author{
Abstract \\ This manuscript is a reflection on the processes and outcomes inherent in the faculty/student co-inquirer \\ relationship. Authors briefly describe their SoTL research project. Subsequently, learning outcomes from \\ the student co-inquirer are discussed in terms of: understanding research and the research process, the \\ impact of the research experience on the student's own teaching and learning, and the impact of the \\ research experience on the student's future professional plans. Lessons learned are shared for future \\ student co-inquirers.
}

\section{Keywords}

scholarship of teaching and learning, metacognition, students as co-inquirers, reflection

\section{Cover Page Footnote}

The authors' names will be released upon publication. 


\section{Description of SoTL Project}

In the spring of 2016, we (Drs. Jen Friberg and Lisa Vinney) offered a semester-long independent study (IS) opportunity for seven undergraduate students in the Department of Communication Sciences and Disorders (CSD) at Illinois State University. This opportunity was focused on the interdisciplinary management of laryngeal cancer, with a specific focus on the following topics:

- Understanding the functions/duties of all professionals who provide services for patients with laryngeal cancer and their families.

- Appreciating the role of the speech-language pathologist (SLP) in working with patients with laryngeal cancer during diagnosis, treatment, and end-of-life care.

- Considering the impact of various laryngeal cancer treatments on respiration, phonation, and swallowing.

- Acknowledging the multi-faceted care many patients with laryngeal cancer might require in addition to SLP services (e.g., counseling, palliative care, respiratory therapy).

As part of this IS experience, students completed assigned readings from Friberg and Vinney (2017) and met weekly to engage in interactive discussions and activities.

Because the management of laryngeal cancer is multi-disciplinary in nature, this IS experience challenged students to examine IS content via the differing perspectives that shape laryngeal cancer management. To this end, IS activities, engaged in by students during weekly discussion meetings, often focused on perspective-taking. Activities were specifically designed to allow students to view clinical scenarios from a variety of viewpoints. The authors were curious if this perspective-driven pedagogy would be impactful in terms of student learning. Thus, they designed a study to investigate learning outcomes resulting from this IS experience.

Over the course of the IS, students completed pre/post IS learning assessments, pre/post IS Metacognitive Awareness Inventories (Schraw \& Dennison, 1994), and weekly reflections to share insights, questions, and comments regarding each week's readings/discussions. The design of this study yielded a great deal of data, so the authors invited an undergraduate student in their CSD program to assist with basic data analysis. While data analysis indicates that perspectivetaking was impactful in increasing metacognitive skills and content knowledge of laryngeal cancer (Friberg, Vinney, \& Smyers, 2016a and b; Vinney, Friberg, \& Smyers, in submission), this paper reflects on the process of building a successful faculty/student co-inquirer relationship over time. Thus, the objective is to support other CSD researchers and students seeking to build collaborative relationships in the context of SoTL research.

\section{Genesis of the Co-Inquirer Relationship: Faculty Perspective}

Because student voices are often underrepresented, there is well-documented movement in the field of SoTL to increase and expand student roles in and engagement with research on teaching and learning (Felten et al, 2013; Welikala \& Atkin, 2014; Werder \& Otis, 2010). Mindful of this, when Ms. Mary Smyers, an undergraduate student, agreed to assist us by becoming involved in our SoTL research in the summer of 2016, we were happy to include her in our work. At that time, we imagined that she would engage (primarily) in rudimentary data analysis, particularly in the transcription and organization of qualitative data collected via student 
reflections. This type of student involvement was characteristic of experiences we had both had with past student research assistants in our disciplinary research. Ms. Smyers finalized her work with data analysis at the end of the summer session, and then expressed enthusiastic interest in continuing her work with the project. Based on her work ethic, insightful questions, and interest in the content of the study, we invited Ms. Smyers to expand her work with our SoTL study. It became apparent early on, that this student was not only very capable, but also extremely interested in taking on a larger, integral role in the research process. In particular, we found excellent reliability between the coding performed by Ms. Smyers and a subset that we performed; which increased our confidence in giving her increasingly greater responsibility. Our trust and confidence in Ms. Smyers was further strengthened by her timely, clear, and professional communication, attentiveness to details, dependability, receptiveness and responsiveness to feedback and direction, and enthusiasm about the research process. Ms. Smyers often noted how she had not previously thought about the study of teaching and learning until becoming involved in this project. She noted interest and excitement in the growth that she documented in student reflections. Having Ms. Smyers in class while she was part of our research team also demonstrated that she was thinking about her own learning differently. She often raised her hand to not only discuss course concepts, but also reflect on her own metacognition.

Thus, in the tradition of Hutchings' visions of the possible (2000), our work with Ms. Smyers defines what might be in terms of our future interactions with student co-researchers. In particular, our experiences support the value of including students as involved co-inquirers in our future SoTL and disciplinary projects. Thus, while Ms. Smyers shares her reflections on her experiences as a student co-inquirer below; we also observed her growth due to her involvement in this project in regards to her own learning inside and outside the classroom, research skills, and understanding of the role of SoTL in advancing fields such as CSD.

Over the course of this project, we also came to understand that several considerations are central to developing a strong and positive faculty/student co-inquirer relationship. Note that several of these concerns would apply to student involvement in traditional, disciplinary CSD research; however, several are focused specifically on SoTL research teams:

1. It is essential for faculty to explain the purpose of SoTL research to potential coinquirers so that they understand that they are not studying CSD content, but rather how CSD students learn that content. When Ms. Smyers joined our research team, she was not sure why we would seek to understand something other than CSD content in our research. A detailed explanation helped her to understand that while SoTL research differed from research she had previously associated with CSD, it was still important work.

2. Share the importance of SoTL research with your co-inquirer so that they understand that their work will have an impact on the learning experiences of future cohorts of students at their institution and beyond. We spoke in depth with Ms. Smyers to help her understand the purpose, scope, and implications of SoTL in CSD in terms of impacting future students' experiences within her program and beyond.

3. Be honest regarding your expectations for students. Determine both your goals and their goals for the co-inquirer relationship. Letting Ms. Smyers know exactly what we considered reasonable, rational, and do-able, supported her open communication with us. 
Removing the specter of uncommunicated expectations allows all stakeholders to enter the co-inquirer process with a shared purpose and direction.

4. Identify students' strengths and match them carefully with research tasks. We found Ms. Smyers to be ideal as a data analyst and, as such, assigned her leadership roles in sorting, analyzing, and organizing thousands of data points for our project. Other tasks may not have been a good match for her (e.g., conducting a literature review), due to limited experience with this sort of task.

5. Develop a system of regular communication to share feedback about the project, questions about the research process, and concerns that might emerge over the course of the co-inquirer relationship. We exchanged weekly emails and met as a team at least once a month over the course of this project. These meetings were critical in ensuring cohesive approaches to our shared work.

6. Consider the implications of short-term versus long-term student co-inquirer involvement in a SoTL project. Weigh project, faculty, and student needs/interests to manage the length of the co-inquirer relationship. While Ms. Smyers was able to be a long-term member of our research team, she had to make difficult choices along the way. When given the opportunity to be a student who took part in the discussion-based laryngeal cancer IS, Ms. Smyers decided to pass on that experience and remain a coinquirer, rather than a student participant in the IS. Ms. Smyers struggle to make this decision reinforced to us that the benefits and drawbacks of short vs. long term coinquirer involvement are context-specific, but must be considered.

\section{Student as Co-Inquirer Reflections: Student Perspective}

Throughout my research experience with Drs. Friberg and Vinney, I supported their work in a variety of ways. Initially, I was responsible for compiling and organizing participants' pre/post IS and weekly reflections for analysis. Subsequently, I worked with Drs. Friberg and Vinney to create codes that captured themes and learning outcomes in students' reflections. Ultimately, we finalized the codes to identify observed student behaviors including questioning directly, expressing curiosity, adding to prior knowledge, making emotional connections, changing prior opinions/perspectives, recognizing learning, reflecting on teaching, expressing surprise, and identifying knowledge. In order to refine our codes and ensure that they accurately portrayed student experiences, this process required a great deal of back and forth communication. For instance, while initially analyzing student's responses, there were several comments that did not seem to fit well into our existing coding categories. After carefully evaluating the cohort's responses, we brainstormed as a team to develop a new code that accurately captured students' expressed ideas. In the end, we decided on a code that I termed significant learning connections for students reflecting connections to material through comprehension, personally, clinically, and through their world lens.

After codes were assigned to all student reflection data, we measured consistency of coding. Inter-rater reliability of assigned codes was measured at over $90 \%$ for over 1600 statements. I continued to be involved in quantitative and qualitative analysis and interpretation of these data and helped to finalize two seminars for presentation at an international teaching and learning conference. Drs. Friberg and Vinney repeated the IS in the fall semester of 2016. Thus, I have begun the process of examining and integrating data from 10 new IS participants with the 
existing data from the prior semester as a long-term co-inquirer with Drs. Friberg and Vinney.

\section{Impact of Co-Inquirer Experience on Understanding the Research Process: Student Perspective}

This project has given me a deeper understanding of research and the outcomes derived from research. I also have a better understanding of why people engage in research. We have hundreds of questions, but sometimes fail to search for answers. Research methods can be employed to answer our questions and facilitate a deeper understanding or facilitate new discoveries regarding a specific topic. Ultimately, research allows humans to continue to question, wonder, and discover the answers to important questions.

I realized that research does not need to focus only on disciplinary topics. In particular, this project highlighted the importance of SoTL research as a tool to understand teaching and learning and observe student learning outcomes. For instance, after reading student reflections across the whole learning experience, I noted that some students made premature conclusions in the early stages of the IS, reflecting inaccurately on topics such as quality of patient care, cooccurring diagnoses, and advocacy for patients. Over time, I observed students questioning their own beliefs to come to more informed and appropriate conclusions.

\section{Impact of Research Experience on Teaching and Learning: Student Perspective}

Being part of this research project has affected the way I view teaching and learning. At first, I viewed teaching and learning as two different processes. After completing this research experience, I learned that a scholarly approach to teaching - using teaching and learning research evidence to make decisions about how to teach - may facilitate improved student learning outcomes. Similarly, instructors' knowledge of learning and how to best facilitate it, will improve their teaching. These ideas are not separate at all, but are closely connected.

Therefore, this project provided me with the opportunity to analyze the way that I teach as an undergraduate teaching assistant. Specifically, Drs. Friberg and Vinney explained the importance of metacognition, the phenomenon where students reflect on their own thinking. Throughout the data collected in our study, I noticed growth in students' thinking and the way that they interpreted their learning. This experience led me to apply my new-found knowledge of metacognition to my work as a teaching assistant. In particular, I began asking students' questions that required them to reflect on course content, as well as, providing students with a variety of options to expand upon their learning. I also incorporated lessons that facilitated deeper understanding of content/material by adding an "applied" component. When students attended their lab section, I was interested in understanding the knowledge obtained. Although students were able to recall information, applying the knowledge clinically was challenging. By adding case study assignments to my teaching, students applied their foundational knowledge to real life scenarios. Including more active learning in my lab section was a direct outcome of my involvement as a research co-inquirer in this SoTL study.

\section{Impact of Co-Inquirer Experience on Future Professional Interests: Student Perspective}


Being part of this research project has increased my interest in understanding the impact of clinicians on the lives of clients and their families. During class instruction, I learned that it is not only essential to understand disorders and how they affect patients, but also how clinical care for a patient is impacted by multidisciplinary care and family interactions. While each patient's case is different, this research project highlighted that it is often beneficial to expand one's viewpoint by taking into account patient, family, and clinician perspectives (beyond CSD practitioners) and priorities in managing disorders that impact communication.

Prior to this experience, I had planned to practice as a clinician for a few years and then work towards a research doctoral degree, specializing in an area of medically-based clinical practice. My involvement in this study has encouraged me to think about pursuing a doctoral degree focused on teaching and learning so that I can add to the evidence-base for effective teaching practices in CSD. I have enjoyed observing students as they learn new content over time. It has been intriguing to see their growth and how they have personally and professionally applied the information from their IS experiences.

\section{Lessons Learned: Student Suggestions for Students Seeking Co-Inquirer Experiences}

Having the support of Drs. Friberg and Vinney helped me understand my role as a co-inquirer for this project. Reflecting on the experience, I can offer the following suggestions for any student seeking to be a member of a SoTL research team:

1. Do not be afraid to seek out SoTL research experiences with faculty members by introducing yourself to faculty members in your program and asking them about their current research. Ask faculty if they are seeking support for current or future SoTL projects or request mentorship for a project of your own, perhaps as an independent study.

2. Immerse yourself in your research project to understand it completely. Read relevant research and ask questions to clarify things that are not evident. In doing so, you'll have more confidence in your work and will be better able to identify important outcomes from the research.

3. Cultivate a collaborative working relationship with all members of your research team throughout the entire research process. Be timely with your communications and follow through on those aspects of the project to which you have committed. Collaborating well unlocks the door for increased opportunities and expanded responsibility.

4. Seek out guidance as needed. Do not be afraid to ask questions! Make sure that if you are not sure about something, you make the effort to seek answers and learn more about your project. The faculty co-inquirer(s) will surely be willing to guide you in producing high quality research.

5. Use what you have learned to guide your future efforts. Think about how SoTL can help you as a student, teacher, clinician, and researcher.

\section{Concluding Thoughts}

Many CSD faculty routinely involve both graduate and undergraduate students in traditional, disciplinary research in CSD, focused in areas such as fluency, voice, child language, or vestibular function. These research experiences have been considered beneficial in supporting 
student learning about the research process, as well as, content learning in CSD. While SoTL is different from disciplinary research in purpose and execution, it is meritorious scholarship (Council on Academic Programs in Communication Sciences and Disorders, n.d.). Further, Friberg (2014) indicated that the benefits of SoTL research for faculty and students must be presented cogently and comprehensively to stakeholders to advocate for involvement in SoTL inquiry. That is what we have attempted to relate within this paper. Our co-inquiry experience has demonstrated that students can realize similar benefits from the engagement in SoTL research as have been observed in disciplinary research. Co-involvement in SoTL research can lead students to better understand the research process (e.g., research design, data collection/analysis, research with human subjects, dissemination of results), varied research methods (e.g., qualitative, quantitative, mixed), and their own learning (e.g., how do CSD students learn best?). Recognizing that we have presented one case study of a faculty/student coinquirer experience, we would suggest that additional examinations of the benefits of these relationships be undertaken to definitively establish SoTL research co-inquiry as an impactful learning experience.

\section{References}

Council of Academic Programs in Communication Sciences and Disorders. (n.d.). SoTL Position Paper. Downloaded from http://www.capcsd.org/academicclinical-resources/sotlposition-paper/

Felten, P., Bagg, J., Bumbry, M., Hill, J., Hornsby, K., Pratt, M., \& Weller, S. (2013). A call for expanding inclusive student engagement in SoTL. Teaching and Learning Inquiry, 1(2), 63-74.

Friberg, J. C. \& Vinney, L. A. (2017). Laryngeal cancer: An interdisciplinary resource guide for practitioners. Thorofare, NJ: Slack Publishing, Inc.

Friberg, J. C., Vinney, L. A., \& Smyers, M. M. (2016a, October). Learning to Tell the Story of Laryngeal Cancer through an Innovative Independent Study Experience. Paper presented at the International Society for the Scholarship of Teaching and Learning Conference, Los Angeles, CA.

Friberg, J. C., Vinney, L. A., \& Smyers, M. M. (2016b, October). Reflecting on the Co-Inquirer Relationship: Navigating the Water of SoTL Research. Paper presented at the International Society for the Scholarship of Teaching and Learning Conference (Council on Undergraduate Research Pre-Conference workshop), Los Angeles, CA.

Friberg, J. C. (2014, December 1). Timing is everything: Working to increase disciplinary acceptance of SoTL. [weblog post]. Retrieved from https://illinoisstateuniversitysotl.wordpress.com/2014/12/01/timing-is-everythingworking-to-increase-disciplinary-acceptance-of-sotl/

Hutchings, P. (2000). Opening lines: Approaches to the scholarship of teaching and learning. Menlo Park, CA: Carnegie Foundation for the Advancement of Teaching.

Schraw, G. \& Dennison, R.S. (1994). Assessing metacognitive awareness. Contemporary Educational Psychology, 19, 460-475.

Vinney, L. A., Friberg, J. C., \& Smyers, M. M. (in submission). Examining the Learning of Students Participating in an Interactive Independent Study Experience. Manuscript submitted to Innovative Higher Education. 
Welikala, T. \& Atkin, C. (2014). Student co-inquirers: The challenges and benefits of inclusive research. International Journal of Research \& Method in Education, 37(4), 390-406.

Werder, C. \& Otis, M. M. (Eds.). (2010). Engaging student voices in the study of teaching and learning. Sterling, VA: Stylus Press. 